\title{
Seizures and Epilepsy in Stroke Patients: An Updated Review
}

\author{
Jacques L. De Reuck \\ Department of Neurology, Ghent University Hospital, Ghent, Belgium \\ *Corresponding Author: Jacques L. De Reuck, Department of Neurology, Ghent University Hospital, \\ Ghent, Belgium.
}

\begin{abstract}
Stroke-related seizures and epilepsy can be subdivided in those of early onset, occurring immediately following the stroke, and late-onset ones, delayed from the stroke by a few months. Very late-ones are a particular type with good outcome and occurring after years following a mild recurrent cerebrovascular accident.

Status epilepticus is frequently associated to the stroke onset, but the recurrence rate of the seizures is rather low. Late-onset seizures can have different clinical presentations and can be related to various causes.

In addition to the investigations concerning the cause of the stroke, and the adequate treatment also an extensive seizure assessment is needed.

Seizures occur mostly in patients with cortical temporal and parietal infarcts with irregular borders on neuroimaging. The severity of the vascular risk factors is an important determinant for the recurrence rate.

The new generation antiepileptic drugs are as effective as the old ones but are less responsible for side effects, in particular concerning the cognitive functions. However, low-dose extended release carbamazepine remains a reasonable and low-cost treatment.
\end{abstract}

Keywords: Stroke-related seizures- incidence and classification- risk factors and location- treatment modalities.

\section{INTRODUCTION}

The importance of seizures has been underestimated in patients suffering from cerebrovascular diseases [1,2]. However, they are responsible for nearly $50 \%$ of newly diagnosed epilepsy among patients over 60 years of age [3].

Repeated seizures or a status epilepticus worsen the neurological and mental condition of stroke patients [4,5]. All most used antiepileptic drugs also promote cognitive harm in the elderly [6].

\section{EPIDEMIOLOGY}

In one study the total prevalence of epileptic seizures related to stroke is estimated $11.6 \%$ with a total annual risk of $4.6 \%$ [7]. Other studies respectively show an incidence rate of $6.93 \%$ [8] and 5\% [9].

Following a stroke 3-6\% develops acute symptomatic seizures within the first 7 days. The rate is higher after cerebral haemorrhage compared to an infarct with in our study an incidence of $10.6 \%$ in the former and $8.6 \%$ in the latter [10]. Unprovoked seizures occur in 10$12 \%$ of stroke patients after more than 7 days
[11]. Seizures or epilepsy can precede strokes in less than $1.5 \%$ of patients of more than 60 years of age [12]. Although the stroke characteristics remain the most important risk factors, firstdegree relative with epilepsy also increases the risk in a multivariate analysis [13].

A low incidence of seizures is observed in patients with lacunar strokes [14,15]. The seizure occurrence in patients with lacunar infarcts is not related to the severity of the stroke but rather to an underlying associated neurodegenerative process [16].

Seizures are not infrequent in patients with leukoaraiosis, who were previously asymptomatic [17]. Positron emission tomographic studies have shown that the seizures are the premonitory signs of a neurodegenerative encephalopathy in these patients, possibly leading to cognitive decline [18].

\section{Classification and Aetiology}

The classification of stroke-related seizures is confusing. Generally they are subdivided in early-onset ones, occurring within 1 week after onset of a stroke, and late-onset ones occurring 
more than 1 week after the cerebrovascular event. Early-onset seizures differ from the lateonset ones by permanent structural changes in the brain [19]. Most of them occur within the first days [20].

The first late-onset attack takes generally place between 3 months and 2 years after the stroke. However still $28 \%$ of the stroke patients develop their first late-onset seizure after more than 2 years. They are frequently the expression of a mild recurrent infarction [21].

Stroke-related seizures should best be classified as those of early-, late- and vey late-onset and those due to a recurrent stroke [22].

In patients with seizures related to an ischemic event $29.7 \%$ is of cardiac embolic origin and $70.3 \%$ due to thrombosis. This is not statistically different from the incidence in non-seizure patients [23]. Early-onset as well as late-onset seizures in spontaneous intracerebral haematomes mainly involve the frontal lobes [24].

Inhibitory seizures of short duration have to be distinguished from transient ischemic attacks. These types of seizures must be mainly suspected in patients presenting a short temporary speech disturbance and partial amnesia for the event [25]

A rare cause of focal seizures is observed in the "reperfusion syndrome" after carotid endarterectomy or stenting for longstanding chronic severe carotid stenosis [26, 27]. In rare instances, it can also occur after administration of recombinant tissue plasminogen activator for acute ischemic stroke [28].

The clinical presentation of the seizures can be subdivided, in simple partial and complex partial ones with or without secondary generalisation and in those to be considered as primary clonic-tonic spells. The rate of simple partial seizures represents $50 \%$, while complex partial spells and primary generalized clonictonic insults are observed in $25 \%$ each [29]. Status epilepticus occurs more frequently at the onset of a severe stroke [30,31]. It can be defined as a seizure lasting more than 30 minutes or recurrent seizures without recovery of consciousness over a period of 30 minutes [32].

A particular type of non-convulsive or inhibitory seizures has been observed on electroencephalograms (EEG) in the absence of focal or general convulsions in patients with a severe acute stroke [33]. It is the cause of a transient worsening of the neurological signs in more than $22 \%$ of patients with a previous stroke [34].

\section{RISK FACTORS}

Diabetes, arterial hypertension, current smoking, low-dose alcohol use, gender and race/ethnicity are not considered as risk factors for the occurrence of early-onset seizures after stroke [35]. Alcohol abuse, on the other hand, is associated with a significantly greater probability of early-onset seizures [36]. In our study chronic obstructive pulmonary disease is found to be a risk factor for stroke-related seizures, mainly in those of late-onset [37]. One study considers that the magnitude of seizure risk and major risk factors are similar between young ischemic stroke patients and old ones [38]. On the other hand younger age is considered as a predictor of recurrence after early- and late- onset seizures [39]. Another study considers a cardio-embolic origin as a more severe risk factor for non-convulsive status epilepticus after stroke [40]. The presence of laminar necrosis and haemosiderin deposition on neuroimaging is also been considered as predictive for the occurrence of post-stroke seizures [41].

Patients with a partial anterior circulation syndrome have a higher risk to develop lateonset seizures than those with a total anterior circulation syndrome, due to shorter life expectancy and more sharply demarcated large infarcts in the later group [42,43]. Cortical infarcts with irregular borders in the parietal and the temporal lobes are the main risk factors to develop late-onset seizures. However, primary generalized tonic-clonic seizures occur mainly in case of infarction of the deep territory of the middle cerebral artery [44]. In one study, cortical watershed infarctions are found to be a higher risk to cause early-onset seizures [45].

\section{DIAGNOSTIC PROCEDURES}

In every elderly patient who develop for the first time a focal or generalized seizure it should be suspected that it could be the first clinical presentation of an acute stroke or be related to a previous non-detected cerebrovascular event. Also every patient with a previous history of a stroke who develops a seizure must be investigated for the possibility of a new cerebrovascular accident [46].

An electroencephalogram (EEG) should be performed as early as possible. 
The most typical EEG findings are periodic lateralized epileptic discharges (PLEDs). They are observed in $6 \%$ of patients with simple early-onset seizures, but their incidence increases up to $71.4 \%$ in case of status epilepticus [47]. 17\% of these patients develop seizures on follow-up [48]. Other frequent EEG findings in early and late-onset seizures are the occurrence in $24.6 \%$ of frontal intermittent rhythmic delta activities. PLEDs are observed in $25 \%$ of patients with early- and only in $1 \%$ of the late-onset [49]. However, the most common EEG findings are localized slowing corresponding to the infarct side [50].

Neuroimaging should be performed as early as possible. Computed tomography (CT) scan can be useful to demonstrate a recurrent infarct. Also the capricious distribution of the cerebrovascular lesion can lead to the suspicion of stroke-related seizures. Cortical hyper perfusion in the acute stage followed by hypo perfusion patterns, crossing the normal anatomical vascular territories boundaries allow the distinction between seizure-related perfusion patterns from ischemic hypo perfusion [51,52].

Magnetic resonance imaging (MRI) is of course more sensitive to detect the location and the extension of the infarct but also the occurrence of a very recent infarct, not yet detectable on $\mathrm{CT}$. The diffusion weighted imaging also allows the demonstration of the secondary damage caused by the epileptic spells $[53,54]$.

Similar as in new stroke patients, those presenting with late-onset seizures should have extensive cardiovascular examination with a $24 \mathrm{~h}$ electroencephalogram and transthoracic echography or eventual transoesophagial doppler examination, in order to detect a possible cardioembolic source. Ultrasound examination of the extracranial carotid arteries has to be performed, eventually followed by an MRI or a conventional angiography [55].

Our positron emission tomography (PET) studies, performed with oxygen-15, show that in infarcts associated to late-onset seizures the oxygen extraction rate in the infarct area is increased, while the blood flow and the oxygen metabolism are decreased compared to those without spells, indicating still active metabolic changes [56,57]. An increase of the cobalt-55 tracer on PET is observed in the border zones of old cerebral infarcts of patients with late-onset seizures compared to those without. This indicates the occurrence additional recent ischemic damage due to the seizure [58].

\section{Prognosis}

Patients with early-onset seizures have a worse outcome and a trend of more status epilepticus [59]. On the other hand seizure recurrence is less frequent [43]. However, they have a high risk of death within 3 years [60]. Acute or remote symptomatic stroke causes approximately $60 \%$ of status epilepticus in the elderly [61].

Patients with late-onset seizures have a recurrence rate of more than $50 \%[62,63]$.

Repeated seizures following an ischemic stroke promote vascular cognitive impairment [5). They can even leads to the occurrence of poststroke dementia [64]. A single seizure, on the other hand, does not affect the disability and the mental status to a significant degree $[4,5]$.

Very late-onset seizures occur in patients with minor ischemic strokes with good recovery and benign disease course [22].

\section{TrEaTMENT}

There are currently no established guidelines for the prophylactic use of anti-epileptic drugs [65]. Only levetiracetam has been proposed as prophylactic treatment following an intracerebral hemorrhage [66].

The treatment options for post-stroke seizures include phenytoin, carbamazepine, valproate acid and the new antiepileptic drugs, that can decrease drug interaction and some adverse effects [67]. No single drug was found to be more effective over others, though the newer ones are associated with fewer side effects [68].

Early-onset seizures have higher incidence of status epilepticus and more stroke-related risk factors, but on the other hand require less continuous use of antiepileptic drugs [69]. Treatment with intravenous administration of benzodiazepines should be started as early as possible. If not effective levetiracetam, phenytoin or valproate can be used [70]. As the recurrence and the appearance of late-onset seizures is rather low in patients with seizures and status epilepticus at stroke onset, maintained antiepileptic drug treatment is not mandatory on discharge from the hospital after the stroke. Only when late-onset seizures eventually appear, one has to start with a sustained treatment [71]. Early intravenous treatment with recombinant tissue plasminogen activator prevents partly the occurrence of late-onset seizures, probably due to a better reperfusion of the ischemic brain regions [72]. 
Overall patients with stroke-related seizures have a good prognosis and are well controlled by antiepileptic drugs. However, up to $25 \%$ become drug resistant [73].

As the first late-onset seizure does not seem to impair cognition, anti-epileptic drugs should only be started in patients with seizure recurrence, similar to the guidelines in traumatic brain disease [74].

Phenytoin should be avoided because of its well-recognized interaction with warfarin and the difficulty of maintaining consisting therapeutically levels of both drugs [75]. Of the old generation of antiepileptic drugs our firstline option is the use of carbamazepine as monotherapy [76]. A more recent study suggested that the best results are obtained with valproic acid and the new antiepileptic drugs [77]. The therapeutically results are similar between carbamazepine and the new generation gabapentin $[78,79]$. Lamotrigine can also be used and is better tolerated than carbamazepine [80].

In some small studies levetiracetam as monotherapy is shown to be effective and well tolerated in elderly patients with post-stroke seizures [81-83]. Also, levetiracetam has significant advantages over carbamazepine on cognitive functions [84].

However, low-dose extended release carbamazepine remains a reasonable and lowcost treatment to be advocated in particular in developing countries [85].

\section{REFERENCES}

[1] Silverman IE, Restrepo L, Mathews GC. Poststroke seizures. Arch Neurol. 2002; 59: 195-201.

[2] Camilo O, Goldstein LB. Seizures and epilepsy after ischemic stroke. Stroke. 2004; 35: 17691775.

[3] Yang H, Rajah G, Guo A, Wang Y, Wang Q. Pathogenesis of epileptic seizures and epilepsy after stroke. Neurol Res. 2018; 40 (6): 426-432.

[4] De Reuck J, Claeys I, Martens S, Vanwalleghem P, Van Maele G, Phlypo R, et al. Computed tomographic changes of the brain and clinical outcome of patients with seizures and epilepsy after an hemispheric ischemic stroke. Eur J Neurol. 2006; 13: 402-407.

[5] De Reuck J, De Clerck M, Van Maele G. Vascular cognitive impairment in patients with late-onset seizures after an ischemic stoke. Clin Neurol Neurosurg. 2006; 108: 632-637.

[6] Mula M, Trimble MR. Antiepileptic druginduced cognitive adverse effects: potential mechanisms and contributing factors. CNS Drugs. 2009; 23: 121-137.
[7] Conrad J, Pawlowski M, Dogan M, Kovac S, Ritter MA, Evers S. Seizures after cerebrovascular events: risk factors and clinical features. Seizure. 2013; 22 (4): 275-282.

[8] Zou S, Wu X, Zhu B, Yu J, Yang B, Shi J. The pooled incidence of post-stroke seizures in 102008 patients. Top Stroke Rehabil; 2015; 22 (6): 460-467.

[9] Stefanidou M, Das RR, Beiser AS, Sundar B, Kelly-Hayes M, Kase CS, et al. Incidence of seizures following initial ischemic stroke in a community-based cohort: The Framingham Hearth Study. Seizure. 2017; 47:105-110.

[10] De Reuck J. Stroke-related seizures and epilepsy. Neurol Neurochir Pol. 2007; 41 (2): 144-149.

[11] Benninger F, Holtkamp M. Epileptic seizures and epilepsy after a stroke: Incidence, prevention and treatment. Nervenarzt. 2017; 88 (10): 1197-1207.

[12] Zelano J, Larsson D, Kumlien E, Asberg S. Pre-stroke seizures: A nationwide registerbased investigation. Seizure. 2017; 49: 25-29.

[13] Eriksson H, Wirdefeldt K, Asberg S, Zelano J. Family history increases the risk of late seizures after stroke. Neurology. 2019; 93 (21): e1964e1970.

[14] Bladin CF, Alexandrov AV, Bellavance A, Borenstein N, Chambers B, Coté R, et al. Seizures after stroke: a prospective multicenter study. Arch Neurol. 2000; 57: 1617-1622.

[15] De Reuck J, Nagy E, Van Maele G. Seizures and epilepsy in patients with lacunar strokes. $\mathbf{J}$ Neurol Sci; 2007: 263 (1-2): 75-78.

[16] De Reuck J, Van Maele G. Cognitive impairment and seizures in patients with lacunar strokes. Eur Neurol. 2009; 61 (3): 159-163.

[17] Maxwell H, Hanby M, Parkes LM, Gibson LM, Coutinho C, Emsley HCA. Prevalence and subtypes of radiological cerebrovascular disease in late-onset seizures and epilepsy. Clin Neurol Neurosurg. 2013; 115 (5): 591-596.

[18] De Reuck J, Decoo D, Boon P, Strijckmans K, Goethals P, Lemahieu I. Late-onset epileptic seizures in patients with leukoaraiosis: a positron emission tomographic study. Eur Neurol. 1996; 36: 20-24.

[19] Altman K, Shavit-Stein E, Maggio N. Poststroke seizures and epilepsy: from proteases to maladaptive plasticity. Front Cell Neursci. 2019; 13: 397 doi: 103389/fncel. 2019. 00397.

[20] Arboix A, Garcia-Eroles L, Masons JB, Oliveres M, Comes E. Predictive factors of early seizures after cerebrovascular disease. Stroke. 1997; 28: 1590-1594.

[21] De Reuck J, Vanhee F, Van Maele G, Claeys I. Magnetic resonance imaging after seizures in patients with an ischemic stroke. Cerebrovasc Dis. 2007; 23: 339-343. 
[22] De Reuck J, Sieben A, Van Maele G. Characteristics and outcome of patients with seizures according to the time of onset in relation to stroke. Eur Neurol. 2008; 59: 225228.

[23] Misirli H, Ozge A, Somay G, Erdogan N, Erkal $\mathrm{H}$, Erenoglu NY. Seizure development after stroke. Int J Clin Pract. 2006; 60 (12): 1536-1541.

[24] De Reuck J, Hemelsoet D, Van Maele G. Seizures and epilepsy in patients with a spontaneous intracerebral haematoma. Clin Neurol Neurosurg. 2007; 109 (6): 501-504.

[25] De Reuck J, Van Maele G. Transient ischemic attacks and inhibitory seizures in elderly patients. Eur Neurol. 2009; 62 (6): 344-348.

[26] Nayor AR, Evans J, Thompson MM, London NJM, Abbott RJ, Cherryman G, Bell PRF. Seizures after carotid endarterectomy: hyperperfusion, dysautoregulation or hypertensive encephalopathy? Eur J Vasc Endovasc Surg. 2003; 26 (1): 39-44.

[27] Ho D, Wang Y, Chui M, Ho S, Cheung RT. Epileptic seizures attributed to cerebral hyperperfusion after percutaneous transluminar angioplasty and stenting of the internal carotid artery. Cerebrovasc Dis. 2000; 10: 374-379.

[28] Hafeez F, Razzaq MA, Levine RL, Ramirez MA. Reperfusion seizures: a manifestation of cerebral reperfusion injury after administration of recombinant tissue plasminogen activator for acute ischemic stroke. J Stroke Cerebrovasc Dis. 2007; 16 (6): 273-277.

[29] De Reuck J, Goethals M, Claeys I, Van Maele G. EEG findings after a cerebral territorial infarct in patients who develop early- and lateonset seizures. Eur Neurol.2006; 55: 209-213.

[30] Velioglu SK, Ozmenoglu M, Boz C, Alloglu Z. Status epilepticus after stroke. Stroke. 2001; 32 (5): 1169-1172.

[31] De Reuck J, Van Maele G. Status epilepticus in stroke patients. Eur Neurol. 2009; 62: 171-175.

[32] Dupont S, Crespel A. Status epilepticus: epidemiology, definitions and classifications. Rev Neurol (Paris). 2009; 165 (4): 307-314.

[33] Carrera E, Michel P, Despland PA, MaederIngvar M, Ruffieux C, Debatisse $\mathrm{D}$, et al. Continuous assessment of electrical epileptic activity in acute stroke. Neurology. 2006; 67 (1): 99-104.

[34] De Reuck J, De Groote L, Van Maele G. Delayed transient worsening of neurological deficits in patients with an ischemic stroke. Cerebrovasc Dis. 2006; 22: 209-213.

[35] Labovitz DL, Hauser WA, Sacco RL. Prevalence and predictors of early seizures and status epilepticus after first stroke. Neurology. 2001; 57 (2): 200-206.

[36] Zhang C, Wang X, Wang Y, Zhang JG, Hu W, $\mathrm{Ge} \mathrm{M}$, et al. Risk factors for post-stroke seizures: a systematic review and meta-analysis. Epilepsy Res. 2014; 108 (10): 1805-1816.

[37] De Reuck J, Proot P, Van Maele G. Chronic obstructive pulmonary disease as a risk factor for stroke-related seizures; Eur J Neurol. 2007; 14 (9): 989-992.

[38] Roivainen R, Haapaniemie E, Putaala J, Kaste $\mathrm{M}$, Tatlisumak T. Young adult ischemic stroke related acute symptomatic and late seizures: risk factors. Eur J Neurol. 2013; 20 (9): 12471255.

[39] Tomari S, Tanaka T, Ihara M, Matsuki T, Fukuma K, Matsubara S, et al. Risk factors for post-seizure recurrence after the first episode. Seizure. 2017; 52: 22-26.

[40] Tomari S, Tanaka T, Matsubara S, Fukuma K, Ihara M, Nagatsuka, Toyoda K. Risk factors for non-convulsive status epilepticus after stroke. Eur Neurol. 2018; 80 (5-6) 256-260.

[41] Castro-Apolo R, Huang JF, Vinan-Vega M, Tatum WO. Outcome and predictive factors in post-stroke seizures: A retrospective casecontrol study. Seizure. 2018; 62: 11-16.

[42] De Reuck J, Goethals M, Vonck K, Van Maele G. Clinical predictors of late-onset seizures and epilepsy in patients with cerebrovascular disease. Eur Neurol. 2005; 54: 68-72.

[43] De Reuck J, Van Maele G, Cordonnier C, Leys D. Stroke-related seizures in patients with a partial anterior circulation syndrome. Acta Neurol Belg. 2008; 108: 135-138.

[44] De Reuck J, De Groote L, Van Maele G, Proot P. The cortical involvement of territorial infarcts as a risk factor for stroke-related seizures. Cerebrovasc Dis. 2008; 25; 100-106.

[45] Denier C, Masnou P, Mapoure Y, SouillardScemama R, Geudj T, Théaudin $M$, et al. Watershed infarctions are more prone than other cortical infarcts to cause early-onset seizures. Arch Neurol. 2010; 67 (10): 1219-1223.

[46] De Reuck J. Stroke-related seizures and epilepsy. Neurol Neurochir Pol. 2007; 41 (2): 144-149.

[47] Mecarelli O, Pro S, Randi F, Dispenza S, Correnti A, Pulitano P, et al. EEG patterns and epileptic seizures in acute phase stroke. Cerebrovasc Dis. 2011; 31 (2): 191-198.

[48] Punia V, Garcia CC, Hantus S. Incidence of recurrent seizures following hospital discharge in patients with LPDs (PLEDs) and nonconvulsive seizures recorded on continuous EEG in the clinical care setting. Epilepsy Behav. 2015; 49: 250-254.

[49] De Reuck J, Goethals M, Claeys I, Van Maele G, De Clerck M. EEG findings after a cerebral territorial infarct in patients who develop earlyand late-onset seizures. Eur Neurol. 2006; 55 (4): 209-213. 
[50] Ryglewcz D, Baranska-Gieruszzak M, Niedzielska K, Kryst-Widzgowska T. EEG and CT findings in poststroke epilepsy. Acta Neurol Scand. 1990; 81: 488-490.

[51] Austein F, Huhndorf M, Meyne J, Laufs H, Jansen $\mathrm{O}$, Lindner $\mathrm{T}$. Advanced $\mathrm{CT}$ for diagnosis of seizure-related stroke. Eur Radiol. 2018; 28 (5); 1791-1800.

[52] Strambo D, Rey V, Rossetti AO, Maeder Ph, Dunet V, Browaeys P, Michel P. Perfusion-CT imaging in epileptic seizures. J Neurol. 2018; 265 (12): 2972-2979.

[53] Achten E, Boon P, Van De Kerckhove T, Caemaert J, De Reuck J, Kunnen M. Value of single-voxel proton MR spectroscopy in temporal lobe epilepsy. Am J Neuroradiol. 1997: 18: 1131-1139.

[54] De Reuck J, Vanhee F, Van Maele G, Claeys I. Magnetic resonance imaging after seizures in patients with ischemic stroke. Cerebrovasc Dis. 2007; 23: 339-343.

[55] Massengo SA, Endze B, Bastard J, Guiziou C, Velmans N, Rajabally YA. Elderly patients with epileptic seizures: in-patient observational study of two French community hospitals. Seizure. 2011; 20 (3): 231-239.

[56] De Reuck J, Algoed L, Decoo D, Boon P, Van Maele G, Strijckmans K, Lemahieu I. Positron emission tomography of post-infarction seizures. J Stroke Cerebrovasc Dis. 1994; 4: 262-266.

[57] De Reuck J, Decoo D, Algoed I, Boon P, Van Maele G, Lemahieu I, et al. Epileptic seizures after thrombo-embolic cerebrovascular infarcts: A positron emission tomographic study. Cerebrovasc Dis. 1995; 5: 328-333.

[58] De Reuck J, Vonck K, Santens P, Boon P, De Bleecker J, Strijckmans K, Lemahieu I. Cobalt55 positron emission tomography in late-onset epileptic seizures after thrombo-embolic middle cerebral artery infarction. J Neurol Sci. 2000; 181 (1-2): 13-18.

[59] Rumbach L, Sablot D, Berger E, Tatu L, Vuillier F. Moulin T. Status epilepticus in stroke. Report on a hospital-based stroke cohort. Neurology. 2000; 54: 350-354.

[60] Knake S, Rochon J, Fleischer S, Katsarou N, Back T, Vescovi M, et al. Status epilepticus after stroke associated with increased long-term fatality. Epilepsia. 2006; 47 (12): 2020-2026.

[61] Towne AR. Epidemiology and outcomes of status epilepticus in the elderly. Int Rev Neurobiol. 2007; 81: 111-127.

[62] Berges S, Moulin T, Berger E, Tatu L, Sablot D, Charlier B, Rumbach L. Seizures and epilepsy following strokes: recurrence factors. Eur Neurol. 2000; 43: 3-8.

[63] Lamy C, Domigo V, Semah F, Arquizan C, Trystram D, Coste J, et al. Early and late seizures after cryptogenic ischemic stroke in young patients. Neurology. 2003; 60: 400-404.

[64] Leys D, Hénon H, Mackowiak-Cordoliani MA, Pasquier F. Poststroke dementia. Lancet Neurol. 2005; 4 (11): 752-759.

[65] Doria JW, Forgacs PB. Incidence, implications, and management of seizures following ischemic and hemorrhagic stroke. Curr Neurol Neurosci Rep. 2019; 19 (7): 37. Doi. 10. 1007/ s11910-019-0957-4.

[66] Mackey J, Blatsioris AD, Moser EAS, Carter RJL, Saha C, Stevenson A, et al. Prophylactic anticonvulsants in intracerebral hemorrhage. Neurocrit Care. 2017; 27 (2): 220-228.

[67] Ferro JM, Pinto F. Poststroke epilepsy: epidemiology, pathophysiology and management . Drugs Aging. 2004; 21 (10): 639-653.

[68] Wang JZ, Vyas MV, Saposnik G, Burneo JG. Incidence and management of seizures after ischemic stroke: systematic review and metaanalysis. Neurology. 2017; 89 (12): 1220-1228.

[69] Kim DW, Oh J. Comparison of new-onset and persistent epilepsy in the elderly. Acta Neurol Scand. 2019; 139 (4): 395-398.

[70] Kapur J, Elm J, Chamberlain JM, Barsan W, Cloyd J, Lowenstein D, et al. Randomized trial of three anticonvulsant medications for status epilepticus. N Engl J Med. 2019; 381 (22): 2103-2113.

[71] De Reuck J, De Groote L, Van Maele G. Single seizure and epilepsy in patients with a cerebral territorial infarct. J Neurol Sci. 2008; 271 (1-2): 127-130.

[72] De Reuck J, Van Maele G. Acute ischemic stroke treatment and the occurrence of seizures. Clin Neurol Neurosurg. 2010; 112 (4): 328-331.

[73] Feyissa AM, Hasan TF, Meschlia JF. Strokerelated epilepsy. Eur J Neurol. 2019; 26 (1): 18e3. Doi: 10.1111/ene.13813.

[74] Temkin NR. Preventing and treating posttraumatic seizures: the human experience. Epilepsia. 2009; 50 (Suppl.2): 10-13.

[75] Silverman IE, Restrepo L, Mathews GC. Poststroke seizures. Arch Neurol. 2002; 59: 195-201.

[76] De Reuck J. Stroke-related seizures and epilepsy. Neurol Neurochir Pol. 2007; 41: 144-149.

[77] Huang YH, Chi NF, Kuan YC, Chan L, Hu CJ, Chiou HY, Chien LN. Efficacy of phenytoin, valproic acid, carbamazepine and new antiepileptic drugs on control of late-onset poststroke epilepsy in Taiwan. Eur J Neurol. 2015; 22 (11):1459-1468.

[78] Chadwick DW, Anhut H, Greiner MJ, Alexander J, Murray H, Garofalo EA, Pierce MW. A double-blind trial of gabapentin monotherapy. International Gabapentin Monotherapy Study Group 945-977. Neurology. 1998; 51 (5): 1282-1288. 
[79] Alvarez-Sabin J, Montaner J, Padro L, Molina CA, Rovira R, Codina A, Quintana M. Gabapentin in late-onset poststroke seizures. Neurology. 2002; 59 (12): 1991-1993.

[80] Gililad R, Sadeh M, Rapoport A, Dabby R, Boaz M, Lampi Y. Monotherapy of lamotrigine versus carpamazepine in patients with poststroke seizure. Clin Neuropharmlacol.2007; 30: 189-195.

[81] Kutlu G, GomcelliYB, Unal Y, Inan LE. Levetiracetam monotherapy for late poststroke seizures in the elderly. Epilepsy Behav. 2008. 13: $542-544$

[82] Belcastro V, Costa C, Galletti F, Autuori A, Puitguidi L, Pisani F, et al. Levetiracetam in newly diagnosed late-onset post-stroke seizures: a prospective observational study. Epilepsy Res. 2008; 82 (2-3): 223- 226.

[83] Kutlu G, Gomcelli YB, Unal Y, Inan LE. Levetiracetam monotherapy for late poststroke seizures in the elderly. Epilepsy Behav. 2008; 13 (3): 542-544.

[84] Consoli D, Bosco D, Postorino P, Galati F, Plastino M, Perticoni GF, et al. Levetiracetam versus carpamazepine in patients with late poststroke seizures: a multicenter prospective randomised open label study (EpiC Project). Cerebrovasc Dis. 2012; 34 (4): 282-289.

[85] Ryvlin P, Montavont A, Nighoghossian N. Optimizing therapy of seizures in stroke patients. Neurology. 2006; 67 (Suppl. 4): S3-9.

Citation: Jacques L. De Reuck, "Seizures and Epilepsy in Stroke Patients: An Updated Review", International Journal of Research Studies in Medical and Health Sciences. 2020; 5(12): 39-45.

Copyright: (C) 2020 Jacques L. De Reuck, This is an open-access article distributed under the terms of the Creative Commons Attribution License, which permits unrestricted use, distribution, and reproduction in any medium, provided the original author and source are credited. 